\title{
Presence in the reading of literary narrative: A case for motor enactment
}

\author{
ANEŽKA KUZMIČOVÁ
}

\begin{abstract}
Drawing on research in narrative theory and literary aesthetics, text and discourse processing, phenomenology and the experimental cognitive sciences, this paper outlines an embodied theory of presence (i.e., the reader's sense of having entered a tangible environment) in the reading of literary narrative. Contrary to common assumptions, it is argued that there is no straightforward relation between the degree of detail in spatial description on one hand, and the vividness of spatial imagery and presence on the other. It is also argued that presence arises from a first-person, enactive process of sensorimotor simulation/resonance, rather than from mere visualizing from the perspective of a passive, third-person observer. In sections 1 to 3, an inter-theoretical argument is presented, proposing that presence may be effectively cued by explicit (or strongly implied) references to object-directed bodily movement. In section 4, an attempt is made at explaining which ways of embedding such references in the narrative may be particularly productive at eliciting presence.
\end{abstract}

Keywords: literary narrative; presence; immersion; imagery; sensorimotor simulation; description.

Lisa's experiment suggests that when we read a novel, our mirror neurons simulate the actions described in the novel, as if we were doing those actions ourselves.

—Iacoboni (2008: 94)

Where experiential phenomena are concerned, it is objective measures that must seek validation by establishing their correspondence with introspective measures, and not vice versa.

— Jack and Roepstorff (2003: xiii)

Semiotica 189-1/4 (2012), 23-48

DOI 10.1515/semi.2011.071
0037-1998/12/0189-0023

(C) Walter de Gruyter 


\section{A. Kuzmičová}

\section{Assumptions and prerequisites}

Let's assume that, at least since about the time of Flaubert, many literary authors have constructed entire passages of their narratives so as to render particular situations spatially compelling, to elicit presence in the reader, the sense of having physically entered a tangible environment, of "being there."1 Let's also assume that, at least since about the same period, most readers have responded to these efforts in a collaborative manner, with vivid imagery arising as a result of successful matching of reading practices to cues intrinsic to the text. Save for a handful of doctrinal readers in literary academia, everybody would probably agree that presence is a key ingredient in the broader phenomenon of reader immersion (see Schaeffer 1999). Leaving aside other similarly pre-conceptual components of immersion - affective appraisal (see Robinson 2007) and emotional response (see Miall 2006), suspense (see Gerrig 1998), or rhythm and flow of inner speech - this paper will make a few elementary proposals toward how spatial imagery alone may be cued in narrative literature, producing presence (and coproducing immersion). Contrary to certain common assumptions, it will be argued that there is no direct relation between the degree of detail in spatial description on one hand, and the vividness of spatial imagery and presence on the other. It will also be argued that presence arises from a first-person, enactive process of sensorimotor simulation/ resonance, rather than from mere visualizing from the perspective of a passive, third-person observer. Overall, the descriptions of presence below aim at explaining how our enjoyment of literature is embodied, thus providing a partial account of what makes reading enjoyable at all.

Given that in most cases there is substantive consensus, even within literary academia, as to which narratives are particularly spatially vivid and which rather categorically resist spontaneous spatial imagery (e.g., Ryan 2001: 120139), prototypical spatial cues ought to be possible to isolate. I will make an attempt at isolating them theoretically, both in terms of narrative content (Which types of content are particularly productive at eliciting presence, and why?) and structure (Which ways of embedding this content in the narrative text are particularly well suited for such purposes?). Interactive media theorists (e.g., Biocca 2002) would classify my endeavor as an attempt at addressing what they call "the book problem," i.e., the conundrum of how to account theoretically for the linear, low-tech medium's capacity to transport readers into virtual three-dimensional environments.

For the sake of argumentation, I will invoke theories and experimental results stemming from a plethora of disciplines: narrative theory and literary aesthetics, research in text and discourse processing, phenomenology, cognitive and experimental psychology, and neuroscience. This eclecticism is not meant to distract the readers from my main object of study, which is the aes- 
thetics of narrative literature, but rather to instrumentally narrow down their focus toward particular instances in the fluent process of reading. I am well aware of the multiple epistemological ruptures between (a) neuronal activity in real world situations, (b) human behavior, and (c) the pre-linguistic experience of such behavior on one hand, and (d) fluent readerly experience of narrative literature as based on (e) the multiple, complex operations of discourse comprehension, some of which may be traceable in (f) the neural substrates of reading, on the other hand. Like neuroscientist Vittorio Gallese and other specialists whose work I will be referring to, however, I am reluctant to believe that each of these phenomena constitutes an impermeable ontological domain of its own. Therefore I will draw a tentative line of inter-theoretical speculation from (a) all the way down to (f), while trying to single out when (d) is most likely to adhere phenomenally to (c). All of (a)-(f) will operate throughout the entire paper, and the key focus will be modulated among its three main sections approximately as follows: 2 (c); 3 (c)-(d); 4 (d).

The argument will be structured so as to facilitate partial testing, and any serious attempt at experimental validation is welcome. Text samples will be taken mainly (but not only) from two works of francophone novelists, both of which have been noted for their spatial, perceptual or situational qualities, as well as for their focus on the quotidian: Alain Robbe-Grillet's (1957) La jalousie (favoring detailed description) and Jean-Philippe Toussaint's (1988) L'appareil-photo (lacking detailed description). Although a great many of my statements about presence cuing will carry the modality of "should," "ought," and the like, I have no intention to set out an aesthetic norm. My objectives are purely descriptive.

The main idea I am advocating can be briefly summarized as follows: A higher degree of spatial vividness, arousing in the reader a sense of having physically entered a tangible environment (presence), is achieved when certain forms of human bodily movement are rendered in the narrative, as compared to when they are not. This applies when the motor content in question is either explicitly mentioned (e.g., "John picked up his wallet and opened it.") or very strongly implied, i.e., inevitable to infer from the viewpoint of local coherence (see McKoon and Ratcliff 1992) — such as in "John checked to see if he had enough change. But the inner pocket of his wallet was empty.", which does not make sense unless the act of grasping and opening a wallet is inferred by the reader. Gallese (2000) suggests that the human motor system should be thought of as the missing thread interconnecting the three domains of neuronal activity, behavior, and experience. I suggest this thread should be thought of as extending all the way down to the vicarious experience elicited in narrative reading, a view toward which we are currently receiving some empirical clues in the form of behavioral and neuroimaging data.

Before proceeding any further, a few prerequisites must be spelled out: 
1. By spatial vividness, I do not mean a detailed situational model held active in the reader's working memory, corresponding to propositions such as: There is another room next to the one the characters are standing in right now; Character $\mathrm{X}$ and character $\mathrm{Y}$ are currently present, but character $\mathrm{Z}$ is not. Nor do I mean the ease of retrieving such detail when necessary, e.g., in comprehending anaphoric reference. Extensive theoretical and experimental work has been done to address these issues, and I will refer to some of it in order to support my claims. By spatial vividness, however, I mean an assumed intensity of the fragmentary, instantaneous, and mostly extremely short-lived spatial imagery prompted by a narrative passage. As empirical studies have shown, experienced vividness of a stimulus does not seem to stand in any direct relationship to memory accuracy (see Ericsson 2003: 6).

2. In fluent reading, imagery is mostly spontaneous and pre-reflective. Unlike the imagery of mental imagery tasks as designed in experimental psychology, where people are trained and explicitly instructed to vividly imagine discrete situations, it is not consciously controlled by the reader - once the reader has made the initial choice to treat the narrative conventionally as narrative literature, i.e., to immerse.

3. By imagery, I do not mean visual imagery only, as has been the case in nearly all theoretical work on perceived vividness in literary narrative so far (e.g., Esrock 1994; but see Esrock 2004). Imagery encompasses any vicarious experience whatsoever of what is most commonly referred to as perception, i.e., exteroception (sight, smell, taste, touch, hearing), but also proprioception (e.g., pain) and, crucially, the senses of bodily movement (the proprioceptive, or kinesthetic, senses, e.g., the senses of limb and organ position, velocity, effort, acceleration and partly balance and touch). ${ }^{2}$

\section{Bodily movement in real world experience}

Hypothetically, the wider the range of sensorimotor modalities simultaneously active in imagery, the more vivid the vicarious experience. However, mental imagery does not seem to come in neatly synchronized multimodal packages. It differs substantially from the structure of real world experience, without the discrete modality tracks necessarily overlapping, or fitting into any preconceived model of spatiotemporal order.

Imagery elicited in the strictly linear process of near-naturalistic language (i.e., fluent discourse) processing, in particular, has been found to follow a modulative logic of gradual meaning integration within sentences, occurring not with each and every noun or verb of sensorimotor content, but rather at distinct "uniqueness points," i.e., nodes of situational disambiguation (examples 
will be provided later on). With constant regard to these assumptions, I speculate that minimal instances of comparable sensorimotor unity (encompassing both proprio- and exteroception) prompting multimodal imagery on the verge of veracity may occur, if ever, when triggered by reference to bodily movement.

What lies behind this accentuation of the motor mode is, apart from introspection, a phenomenologically and neuroscientifically informed view of movement, interaction, and agency as formative of and intrinsic to all actual perception. "The world makes itself available to the perceiver through physical movement and interaction," writes Alva Noë (2006: 1), one of several philosophers who have recently made an effort to reconcile the two domains of knowledge in order to advocate a centrality of bodily movement in perception, cognition, experience, and subjectivity (see also Berthoz and Petit 2008; Gallagher and Zahavi 2007; Sheets-Johnstone 1999). Among many other pieces of evidence, Noë refers to the clinical cases of congenitally blind patients who remain "experientially" blind for some time after their cataracts have been removed, taking people's faces for blurs in their visual field, because their visual sensations are still decoupled from patterns of movement. Noë infers that vision in the sense of a conscious experience of size, shape, voluminousness, and distance of an object is always due to the perceiver's sensorimotor understanding, based on previous eye- and body movements related to that or a similar object. As for the neuroscientific branch of this rather broadly conceived and by all means philosophically disparate - intellectual community, Rizzolatti and Gallese (1988) showed already in the 1980s that the mere process of visually attending to an object is partly based on covert preparation of a bodily action to be borne upon that object, a finding that has been repeatedly replicated ever since (see Berthoz and Petit 2008).

Moreover, in real world experience, bodily movement is formative, in a literal sense of the word, of so called peri-personal space, i.e., the space immediately adjacent to the head, arms and legs, constrained by their instantaneous action radius. Interestingly, unlike other extraneous stimuli, any stimulus that enters the nearest strata of peri-personal space - the "gelatinous medium surrounding our bodies" (Graziano and Gross 1995: 1031) — has been found to be cortically coded in a multimodal fashion, with the very same neurons responding to the stimulus regardless of whether it is audial, visual or tactile (see Serino et al. 2006). This phenomenon is commonly manifested in daily experience: we tend to sense the presence of new objects, let alone moving creatures, in our peri-personal space without having to see them first.

If presence is an effect of spatial vividness, in which the motor and sensory modes should optimally converge, and if the physical world we live in is not truly perceived and experienced unless interacted with via bodily movement (be it overt or covert), then the reader's sense of having physically entered a tangible environment must somehow be linked to narrative renditions of bodily 
movement. Furthermore, the fictional world thus entered is unlikely to feel literally tangible unless physical stimuli are mentioned to occur within the moving literary character's "gelatinous medium," i.e., unless the furnishing of the fictional world is reached, grasped, manipulated, leaned against, etc. In other words, the most stimulating movements of them all ought to be volitional transitive movements, particularly when object-directed, as opposed to self-, person- or animal-directed. Volitional movements entail particular attentional focus on the environment interacted with, such that is absent from reflexive or otherwise unintended movements (see Allport 1987). As indicated above, perception is currently being viewed by scientists and philosophers alike as an auxiliary of action. I suggest that in the linear process of reading, the relation is often the reverse: the object-directed movement of a literary character may, especially under certain conditions to which I will proceed later, prompt a vivid multimodal image of the environment it is being performed in and upon.

\section{The literary character's bodily action visualized versus simulated}

Until this point, the main claim of my argument has not diverged radically from that of agency theoretician Thor Grünbaum (2007). Grünbaum makes the helpful distinction between "summarizing action-narration" ("In the company of a Dane and two Norwegians I left the old Lübeck in the evening ...") and narrative renditions of "bodily movements" ("He moved a thin shrunken brown hand gently in the air in time to his praise ...") on one hand, and narrative renditions of "simple bodily actions" ("[She] pulled the blind, leaned her brow against the cool pane ...") on the other. The latter may seem to correspond roughly to what I have in mind when accentuating transitive bodily movement, because in phenomenological thought, on which Grünbaum is equally prone to elaborate, transitive movements (when volitional) are a subset of bodily actions, since the term "action" covers purposeful movement in general (e.g., Gallagher and Zahavi 2007). Simple bodily actions, Grünbaum argues, usually come short of theoretical treatment in plot-narratology (e.g., the work of Ruth Ronen), which attends mostly to summarizing action-narration, as well as in discourse-narratology (e.g., the work of Gérard Genette), which would rather tend to study the technique of rendition employed in the case of bodily movement (as defined by Grünbaum). Simple bodily actions do serve a distinct function in narrative, nevertheless, which Grünbaum identifies in rather general terms as a "visualizing" function. At this point, my approach departs from Grünbaum's.

I agree that in order to stimulate the reader's imagery, a bodily movement must be comparably dynamically veracious, i.e., that the time the text passage takes to read ought to be commensurable with the duration of the movement as 
performed in the real world. This is in part what distinguishes Grünbaum's simple bodily actions from summarizing action-narration and narrative renditions of bodily movement, although Grünbaum does not spell it out that way, his major focus resting elsewhere. What I disagree with is Grünbaum's assumption that dynamically veracious bodily actions are normally visualized from a third-person perspective, as if the reader were on scene in the position of a detached witness (mere kinematic veracity would suffice in such case; see Schwartz 1999 for the distinction). Rather, I suggest that they are often simulated from a first-person perspective, which is primarily what makes them a vehicle of presence and immersion. Imagery, as has been pointed out, encompasses all sensorimotor modalities, including the utterly private cutaneous sense responding vicariously to the cool windowpane mentioned in one of Grünbaum's above literary examples. Hence when I claim that the character's bodily movement prompts a vivid multimodal image in the reader, I assume that the reader experiences the phenomenon of motor simulation, in discourse studies also known as motor resonance, one of several kinds of motor imagery, accompanied by sensory traces related to the movement in question (proprioception) and to the object it is directed at (exteroception). The resultant flash of sensorimotor unity may in some way feed on what physiologists call the "motor schema" (see Schmidt 1975), i.e., a relational memory schema linking action to its sensory outcome.

Motor resonance stands for the referential "covert movement" that has been unequivocally demonstrated, both in behavioral and neuroimaging experimental setups, to occur when literal (i.e., non-metaphorical, non-idiomatic) bodily movement sentences are processed (see Fischer and Zwaan 2008 for a review). When people listen to or read sentences referring to bodily movement, the motor and pre-motor areas of their cortices become somatotopically activated - the hand area of the motor strip responding to hand-related action words, the feet area to feet-related action words etc. (e.g., Raposo et al. 2009; AzizZadeh et al. 2006). When they need to perform a motor task, e.g., manually rotate a knob, in order to make their way through a sentence (so called readingby-rotation), their motor performance is speeded up or slowed down if the sentence refers to a similar movement performed in the same or opposite direction, respectively. Numerous behavioral studies in the field have been conducted by cognitive psychologists Rolf Zwaan, Lawrence Taylor and colleagues (e.g., Zwaan et al. 2010; Taylor and Zwaan 2008; Taylor et al. 2008; Zwaan and Taylor 2006; Zwaan 2004), who not only study motor resonance, but focus equally on visual motor imagery (vicarious visual perception of moving objects) and other forms of visual simulation in discourse processing. As for neuroimaging, convergent results from a first study of sensorimotor simulation in which the experimental stimuli consisted of entire narrative passages (27 clauses each) have recently been obtained (Speer et al. 2009). 
In other words, if a theory of language comprehension elaborating on the principles of naïve realism - self-evident perhaps from the viewpoint of many literary scholars - would have brought about ridicule among cognitive scientists only a couple of decades ago, experimental evidence supporting such theories abounds today. The theories of language outlined above have been labelled as "perceptual," "grounded," "embodied," as "theories of simulation/ resonance," and so forth, while merging into the broader theoretical frameworks of "embodiment" (e.g., Varela et al. 1991), "grounded cognition" (e.g., Barsalou 2008; Pecher and Zwaan 2005) and "situated cognition" (e.g., Robbins and Aydede 2008).

As mentioned above, motor resonance appears - and so does reportedly its perceptual counterpart - to be modulated in accordance with gradual semantic disambiguation and instantaneous linguistic focus (e.g., Taylor and Zwaan 2008; Taylor et al. 2008; Zwaan and Taylor 2006). For example, the two sentences "John opened the beer can."|"John opened the book." differ substantively as to what kind of movement is covertly simulated in the process of resonance. Indeed, resonance in such cases has been found to reach its peak of intensity as the reader is processing the "uniqueness point," i.e., the postposited disambiguating object noun ("the beer can" versus "the book") and/or an action-related (e.g., "quickly") — as opposed to merely agent-related (e.g., "obediently") — adverb, should there be any.

These exemplary sentences call for a brief exposition on affordance, a phenomenon closely related to motor imagery and resonance. The term was given currency in James J. Gibson's (1979) ecological theory of visual perception, capturing the utterly interactionist nature of sensory attention, eventually confirmed by Rizzolatti and Gallese (see above) and many others. Affordance stands for the interaction potential of each and every object in the environment, as constrained by the object's shape, weight, volume, and other properties on one hand, and the motor capacities of the perceiving individual on the other.

While Gibson ascribed affordance to artifacts (i.e., manufactured objects, also called tools), natural objects, and animals alike (a tree affords climbing, a horse can be ridden on), current cognitive science reserves the term, alternately narrowed down to "microaffordance" (e.g., Borghi 2005; Ellis and Tucker 2000), for hand-manipulable artifacts primarily. The reasons for this terminological shift are multiple. For example, subjects in neuroimaging (e.g., Grèzes et al. 2003; Chao and Martin 2000; see Martin 2007 for a review) and behavioral (e.g., Glover et al. 2004; Tucker and Ellis 2004; Tucker and Ellis 2001; Ellis and Tucker 2000; Tucker and Ellis 1998) experiments display accurate somatotopic cortical activation (simulation of hand movement in the pre-motor cortex triggered automatically by the word "hammer") or resonance (faster manual task response if the content of a stimulus affords the same hand movement as required by the task), respectively, when exposed to pictures or names 
of artifacts, but not when exposed to pictures or names of natural objects or animals. This is probably due to the fact that artifacts have canonical ("hammer"-"grasp the handle with a power grip, lift and pound") and noncanonical ("hammer"-"plant in the soil") affordances, which is not usually the case with natural objects and animals (see Borghi 2005). ${ }^{3}$

For each individual to be capable of performing the various motor tasks of daily life, the motor circuitry is assumed to feature a vast register of distinct motor programs (e.g., Engelkamp and Zimmer 1984). Because of affordances, these motor programs are more complex and fine-grained for transitive than for intransitive movements. The difference is assumed to affect motor resonance, with transitive movements eliciting more resonance than intransitive ones, provided they are volitional. Non-volitional movement sentences such as "John stumbled." have been predicted to elicit no resonance at all, as our repertoire of motor programs is limited to volitional movements exclusively (see Zwaan et al. 2010), yet another argument in favor of the aforementioned precondition of volitionality.

To operate with this precondition when studying simple bodily actions in narrative may be difficult, because utterances like "I accidentally grasped the handle of the dagger with my hand." are sparse in literature, with the exception of stories where the bodily movement in question connects to other events as does for instance the movement of Emma's lover-to-be in Flaubert's $\mathrm{Ma}$ dame Bovary: "Sans qu'il s'en aperçut, tout en causant, Léon avait posé son pied sur un des barreaux de la chaise où Madame Bovary était assise." (Flaubert 1999 [1857]: 166) ["While he talked, Léon had unconsciously placed his foot on the bar of Madame Bovary's chair." (Flaubert 1995 [1950]: 97)]. In other words, volition and intentionality of transitive bodily movement is rather instantaneously inferred and mostly presupposed — in the affirmative — by the reader, as is continuously guessed the action's significance for the story plot. The issue of perceived intentionality in reading, however interesting, falls outside the scope of this paper. Suffice it to point out that, as far as real life movement observation is concerned, transitive movements are much more readily judged intentional than intransitive ones (see Jeannerod 2006: 102).

Quite naturally, in comparison to other transitive movements, those directed at objects with canonical affordances, such as beer cans, books, hammers and daggers, provide more powerful clues (eventually verified or not) to the observer or reader about what agent intentions may be involved. Thus, in addition to being volitional, transitive, and dynamically veracious, the most immersive bodily movements of them all ought to be movements directed at everyday artifacts. The more familiar the object vicariously acted upon, whether in a canonical or a non-canonical manner, the stronger the movement's immersive potential in terms of resonance and multimodal imagery (see also Lewis 2006). ${ }^{4}$ 


\section{Enactment eliciting presence}

An important question may arise at this point: If resonance is intrinsic to naturalistic language comprehension in general, what explanatory value do these findings have for literary aesthetics in particular? A brief version of the answer would go approximately as follows: It is my conviction that in reading literary narrative, sensorimotor resonance is being continuously boosted toward the threshold of consciousness, its peaks and valleys of intensity being more robust than in non-literary reading (yet following a logic not completely dissimilar from that of situational integration within the stimulus sentences and textoids used in experimental psychology). All resonance of such variety will further be distinguished as enactment. Thanks to enactment and the associated sense of presence, we feel that we undergo vicarious experience even when engaging with "physical stories" (see Mar 2004), i.e., literary narratives which, similarly to Toussaint's L'appareil-photo, invite comparably little attribution of mental states to characters. Based on introspection, I argue that occasionally, enactment refrains from being merely pre-reflective, entering the reader's secondorder awareness, and that it sometimes elicits a level of muscular activity that is not only amenable to self-report, but draws instant attention of the reader to itself. Although in reading "[Pooh] stood on a chair, and took down a very large jar of honey from the top shelf." (Milne 1992 [1926]: 61), the reader never maintains the belief that she has moved herself, she can still experience the coming into being of Winnie-the-Pooh's clumsy power grip as the bear is getting hold of the jar.

Now it is commonplace that literature of the nineteenth century and beyond often makes us sensitive to perceptual aspects of daily experience that are normally passed unnoticed. This axiom has laid in the heart of literary aesthetics since the early twentieth century. Defamiliarization as such, whether referential as initially captured by Viktor Shklovsky's (1990) theory of "estrangement," or purely linguistic as first addressed in Jan Mukařovský's (1976) theory of "foregrounding," receives the main portion of credit whenever a piece of written discourse is recognized for its aesthetic qualities. I have no intention to dispute this idea. Neither am I interested in delving into a history of the human sensorium and the evolving practices of reading, because I understand it to be just as much commonplace that presence, a perceived naturalness of spatial experience, shapes the impact of whatever narrative one is reading (see also Green 2004). What I intend to do instead is tentatively identify the optimal balance between defamiliarization and naturalness, outlining in rather general terms which literary treatment of (dynamically veracious, transitive) bodily movement may elicit presence at its best. The diachronic aspect needs to remain bracketed.

Given what has been established about the reader's introspective access to presence, the task of defining the forms of enactment that most directly induce 
a sense of presence, double as presence already is in its unique position in between naturalness and defamiliarization, splits into another two questions, whose intent differs but in degree: When does enactment elicit presence? (Subsection 4.2) When is presence-eliciting enactment most likely to transgress the threshold of readers' awareness? (Subsection 4.3) Before these two questions are answered, further prerequisites concerning presence as such must be put forward.

\subsection{Presence as background}

Even though occasionally attended to by the reader, presence as a continuous function of a particular reading session or a series of some such sessions operates in the background of higher cognitive processes involved in literary comprehension. Not only so in the self-evident sense that it does not interfere with the fluency of reading, but also in that it leaves space for evaluative thought on the part of the readers, who may find themselves busy making predictions concerning the plot, or associating the events to their own private concerns, or even reinterpreting them more audaciously in accordance with hermeneutic or whichever semiotic patterns. This is possible thanks to the instantaneous and extremely short-lived nature of the vivid spatial imagery triggered by presence cues. Contrarily to what some adversaries of immersion theory and similar concepts might think, the idea of presence does not suggest that the reader is following the narrated events "from within," exclusively and consistently, throughout the entire text.

For a narrative as a whole to elicit a stable level of presence, references to comparably dynamically veracious, transitive bodily movement ought to be scattered evenly throughout the text. In this respect, there is a rather telling contrast between Toussaint's L'appareil-photo and Robbe-Grillet's La jalousie. Both novels begin in a "scenic" manner. In their opening sequences - crucial as these are for further adjustment of readerly expectations - bodily actions are being acted out in clearly indicated environments, rather than displaced or abstract events of a wider time span being summarized. If one takes a portion of text from the very beginning of L'appareil-photo (corresponding roughly to a volume of 4,000 words) and a commensurable portion from the very beginning of La jalousie, and counts the number of explicit or strongly implied references to transitive bodily movement, the quantities amount to 114 for the first 21 pages of L'appareil-photo (about 190 words per page) and 35 for the first 24 pages of La jalousie (about 170 words per page). In L'appareil-photo, the number of occurrences per page is comparably stable -0 ( 2 pages), 1-6 (11 pages), 7-12 (8 pages) - and evenly distributed throughout the text, whereas in the sample taken from La jalousie, the references are accumulated 
in a few clusters of mostly three pages at a time. Each cluster is followed by another two to three pages with no references to transitive bodily movement whatsoever, despite the fact that acting humans are reported to be perceived. The quantities per page are: 0 (12 pages), 1-3 ( 9 pages), $4-6$ ( 3 pages). These opening excerpts are representative of the two novels at large. Toussaint refers to transitive bodily movement at least three times as often as does RobbeGrillet, a striking disproportion, given that La jalousie is construed as a finegrained, circular account of that which is being seen by a man obsessively observing the behavior of others. Meanwhile, L'appareil-photo could be characterized as a straightforward, nearly conversational, first-person account of a few episodes from everyday life. Importantly, during each of the long, fully static "pauses" occurring in La jalousie, any hitherto conceivable sense of presence collapses, leaving the reader with a strong sense of detachment instead, one that in my view prevails more or less throughout the entire novel.

Hence the rules and patterns of presence seem to resemble of the mood-cue system in film structure and spectatorship outlined by film scholar Greg Smith: to sustain presence, the text must provide the reader with a "periodic diet" (Smith 2003: 42) of references to bodily movement. An "optimal" density of cuing seems uneasy, but also unnecessary, to define. Overexposure to raw presence cues as characterized until this very point, such that would cause saturation and loss of effect, remains hypothetically possible. Yet such a narrative would most probably not invite much aesthetic appreciation, approximating a mundane instruction manual instead. I will now return to the aforementioned balance between naturalness and defamiliarization. In so doing I will narrow down my definition of the cues in question here, and describe presence in terms of its very local and instantaneous - rather than global and continuous nature, a step that will further clarify why there should be little risk of cue overdose, if any.

\subsection{Presence as (unmarked) balance}

What I mean by balance between naturalness and defamiliarization in rendering transitive bodily movement happens to be closely related to a notion of unmarked proportion between the kinesthetic, the proprioceptive, and the exteroceptive aspects of the narrated event. That is, not only should the agentobject interaction as described in the narrative ideally not transgress a certain level of granularity, because then it would most probably slide into a kind of slow motion and cease being dynamically or kinematically veracious; it also needs to display some similarity with the distribution of attentional focus such as would normally occur in a corresponding real world action. 
With the exception of stories where artifacts themselves are invested with high conceptual significance (Edgar Allan Poe's 1984 [1844] Purloined Letter, Georges Perec's [1965] Les choses), nearly any narrative rendition of objectdirected movement as such constitutes a vehicle of defamiliarization - in the very general sense that it makes explicit the "gapped middle," or "penultimate subevent" (see Talmy 2000), i.e., a typical subgoal in a more complex sequence of actions. Classified as "minor detail" by discourse theorist Catherine Emmott (1997: 243), the sole act of, for example, pushing a door open, would usually not be included in a non-literary narrative if not implying or leading to something rather unusual, the less would it be considered a full-fledged event worth telling in daily conversation. On the other hand, in the literary cases where it fulfills the function of a presence cue, its way of defamiliarizing experience would not stretch too far beyond its being simply and briefly mentioned, as in the following excerpt from L'appareil-photo:

Profitant d'une légère accalmie, nous nous remîmes en route, et, après avoir marché une bonne demi-heure sous la pluie, comme nous passions devant un grand hôtel, je proposai à Pascale de nous y arrêter pour boire un café, ou même un thé si elle voulait, j'étais prêt à tout. A tout. Je poussai la porte de l'hôtel et aperçu un portier en habit d'apparat, redingote et gilet gris, qui faisait une petite pause dans le hall sur une chaise de service. (Toussaint 1988: 88)

[Taking advantage of a slight lull, we went on our way, and, after having walked for a good half-hour in the rain, as we passed a large hotel I asked Pascale if she would like to stop and have coffee, or even tea if she preferred, I was up for anything. For anything. I opened the hotel door [pushed the hotel door open] and caught sight of a doorman in full regalia, frock coat and gray waistcoat, who, seated in a lounge chair, was taking a break in the lobby. (Toussaint 2008: 77)]

For exactly in cases like this one, does it ever so closely resemble the prelinguistic real world experience of motor interaction - which belongs to the domain of procedural, i.e., non-declarative knowledge - thus becoming a vehicle of experiential naturalization. Otherwise, the unmarked proportion between kinesthesia, proprioception, and exteroception, or the flash of sensorimotor unity as I call it elsewhere in this paper, may fail to arise, with other effects, embodied or disembodied, arising in the reader instead.

Defining kinesthesia, physiologist Alain Berthoz poses the following rhetorical question (Berthoz 2002: 25): "By what twist did language suppress the sense most important to survival?" It is aptly answered by Anthony Marcel, medical scientist and philosopher, who affirms that, as a rule, we have very poor direct proprioceptive awareness when carrying out a bodily action, and reminds us that we tend to be primarily focused on the object we are interacting with (Marcel 2003: 67). Hence my premise that simulated transitive movement 
may serve well to elicit a multimodal image of the outer environment acted upon, and my belief that simple mentioning of the movement does the best work in making both the movement - be it mundane (e.g., pounding a nail into a wall) or extraordinary (e.g., picking up a coin with one's foot, stepping on a nail) - and the immediate environment as veracious as possible in the reader's mind.

A perfectly adequate distribution of attentional focus is again impossible to define, as the situations in which a movement occurs can vary endlessly. Nonetheless, based on what has just been said, one can at least assume that a sense of disproportion easily arises when inner sensations are accounted for, especially if richly so. Proprioceptive accounts may well enhance embodied "empathy" and draw the reader's attention to the processes inside her own body (see also Esrock 2004), but they do not in themselves elicit presence, a phenomenal sense of connection between body and environment. To a certain degree, nearly whatsoever movement escapes verbalization in terms of proprioceptive sensations, as long as the latter conform to what is perceived as common. Still the proprioceptive element is particularly evasive to secondorder awareness when the movement in question is transitive. Marc Jeannerod (2006: 53-54), a physiologist and philosopher who defines motor imagery in line with the main argument of this paper - as action that merely lacks an overt execution phase, points out that object-directed actions (i.e., purposeful object-directed movements) only enter full consciousness in their own right when they are either delayed due to an obstacle, incomplete, or blocked.

Given that presence stands for the sense of existence within a particular environment, the exteroceptive cue in the form of an object must thus remain in focus if presence is to arise at all. An extensive proprioceptive account of one singular transitive movement, uneasy to imagine and difficult to find in actual narratives as it is, would violate the balance. Yet in arousing presence, there is equally an upper limit for what qualifies as natural focus toward the exteroceptive side of the sensorimotor continuum. Contradicting the economy and selectivity intrinsic to normal attention, meticulous descriptions of the outer world may paradoxically make it quite difficult for the reader to imagine what is being described, or even cause her to refocus onto the linguistic medium as such rather than imagine anything at all. Much of this paper, similarly to Grünbaum's paper, stems from an effort to explain that in contrast to what is often assumed, passages of detailed visual description usually do not elicit presence. Not unless an obviously dynamic, bodily element is interspersed throughout; not as long as they are static and conform to the stereotypical, narrow definition of description as "a narrative pause interrupting the presentation of the chain of events" (Pflugmacher 2008 [2005]: 101). Robbe-Grillet's novel, for instance, abounds in detailed environment descriptions, such as the following: 
Sur la table de la salle à manger, le boy a disposé un unique couvert, en face du buffet long et bas qui occupe presque toute la cloison entre la porte ouverte de l'office et la fenêtre fermée donnant sur la cour. Les rideaux, qui n'ont pas été tirés, laissent à découvert les six carreaux noirs de la fenêtre./ Une seule lampe éclaire la grande pièce. Elle est située sur la table, dans son angle sud-ouest (c'est à dire du côté de l'office), illuminant la nappe blanche. (Robbe-Grillet 1957: 144-145)

[On the dining room table the boy has set a single place, opposite the long, low sideboard which takes up almost the entire wall between the open pantry door and the closed window overlooking the courtyard. The curtains, which have not been drawn, reveal the six black panes of the window./ A single lamp illuminates the large room. It is placed on the southwest corner of the table (that is, toward the pantry), lighting up the white cloth. (Robbe-Grillet 1965: 104)]

Although these descriptions may evoke the path of a traveling gaze, any bodily movement or locomotion of the central experiencer would have to be inferred by the reader on rather unsteady grounds.

Thanks to the highly repetitive structure of La jalousie, some readers may be able to reconstruct a decently accurate spatial model by the time they reach this particular passage in the novel. Nonetheless, experimental studies have shown that even spatial modeling, i.e., the deliberate retrieval of spatial information from memory, is significantly facilitated when readers expect a story character to be reported to move, as opposed to when they do not (see Rapp et al. 2006). ${ }^{5}$ Mental modeling notwithstanding, the unusual poverty in references to bodily movement in the above passage prevents one from simulating active physical contact between body and environment, and from developing a sense of having delved into that environment. By contrast, the following passage from L'appareil-photo enhances presence through consistent "dynamization" of the environment:

Comme elle avait vraiment très froid, elle finit par se lever, le manteau sur les épaules, et, écartant du bras un petit rideau de chintz, partit à la recherche d'un chauffage d'appoint dans un réduit minuscule, très sombre, où, dans une douche désaffectée, à côté d'un anorak azur qui pendait à un cintre, avait été entreposées plusieurs piles de documents. Elle m'avait demandé de la suivre pour l'aider dans ses recherches et, tandis que je feuilletais pensivement quelques vieux dossiers d'inscription dans l'obscurité, elle déplaça une caisse mal fermée de laquelle dépassaient des cônes de stationnement orange et attira vers nous une bouteille de gaz, que surmontait un petit radiateur, au foyer grillagé. (Toussaint 1988: 24-25)

[As she was really cold, she got up, a coat covering her shoulders, and, pushing aside a chintz curtain [with her arm], left to look for another portable heater in a tiny dark storage room, where, in a shower no longer used, next to an azure anorak dangling on a hanger, were stacked several piles of papers. She had asked me to follow her to help her look and, while I pensively flipped through some old registration applications in the 
darkness, she moved a poorly closed box spilling over with orange parking cones and found [pulled toward us] a small propane tank for cooking topped with a little radiator with a grilled front. (Toussaint 2008: 22)]

Put differently, in a literary narrative, implicit object affordances alone usually do not suffice for interaction dynamics, and the subsequent sense of presence, to arise. If scholars discussing presence in high-tech virtual environments can advantageously ground their reasoning in a broadly defined concept of affordance, arguing that the virtual environment "is perceived and understood by mentally combining potential patterns of actions" (Schubert et al. 2001: 267), it is precisely because the computerized interfaces they study actually entail real motor interaction on the part of the user, who is kept busy manipulating the joystick, the keyboard, or the like. As far as the book medium is concerned, interaction can only be vicariously enacted by the reader based on a character's reported motor activity, or preparation for some such. The latter may arouse event-related potentials (i.e., simulation of inchoate muscle tension, etc., intrinsic to action preparation; see Kilner et al. 2004; Zwaan et al. 2010) rather than full-fledged motor resonance.

Moreover, behavioral experiments (Borghi and Riggio 2009) show that despite the above mentioned cortical activation detected in the processing of isolated artifact nouns, it is unlikely that in sentences or discourse, these nouns activate a particular action - i.e., one corresponding to the canonical affordance (e.g., "hammer"-"pound") — by default, regardless of the specific task referred to in the surrounding text. Rather, the motor information activated by the object name seems to be modulated by the co-occurring verb (e.g., "see" versus "grasp"). In line with the main argument of my paper, the same experimenters suggest that reader simulation is much more precise for action sentences than for observation sentences. To rephrase my formulation from above: Given that presence stands for the sense of existence within an environment, not only the exteroceptive cue in the form of an object, but also the bodily movement itself must always remain in focus. As far as presence is concerned, one cannot do without the other.

How a bodily movement ought to be rendered in order to appear veracious and facilitate enactment inducing presence, has already been foreshadowed in various ways. It has also been said that if presence is to reach a peak, proprioceptive and kinesthetic cues should be comparably restricted, regardless of whether the movement in question is mundane (canonical) or extraordinary. To adopt a similarly simplistic language, these two kinds of bodily movement can be directed at two different kinds of objects: mundane (basic-level, e.g., "hammer") or extraordinary (parts of mundane objects, or objects less commonly interacted with at a particular place and time). All of these distinctions are certainly a matter of degree, and partly also of individual reception. I 
fully omit transitive movements that strongly contradict human biomechanics (e.g., picking up a hammer with one's foot) or semantic sensibility (e.g., squeezing a window; see also Klatzky et al. 1989), assuming that, albeit stimulating to the reader's embodied imagination, these may be difficult to enact at all.

The more mundane and/or basic-level an object, the less exteroceptive, i.e., in most cases visual, description is required. In fact, for artifacts of daily use proper, the proportion between amount of text and the sense of presence may be a roughly reverse one: only when such artifacts are passed comparably unnoticed does the environment emerge as truly lived, rather than contemplated upon, like in the following passage from L'appareil-photo:

Elle rentra aussitôt et, pendant qu'elle répondait, j'attendis en face d'elle, déplaçant des objets du bout de doigts sur son bureau, ouvrant quelque registre. Dès qu'elle eut raccroché, elle me demanda où j'en étais dans la constitution de mon dossier, et nous fîmes ensemble une manière d'inventaire de tous les documents que j'avais déjà réunis. (Toussaint 1988: 10)

[She went to answer it and, while she was talking, I waited next to her, slightly moving objects on her desk [with my fingertips], opening random drawers [some folders]. Once she had hung up, she asked me how my application was coming along, and together we made a sort of inventory of all the documents I had already gotten together. (Toussaint 2008: 9-10)]

Much has happened in cognitive science since its early times, but it will always remain true that sensory experience escapes replete verbal report into a much higher degree than other, "higher" forms of cognition do. Moreover, the borderline between verbally evoking and conceptualizing is especially thin when perception of quotidian artifacts is concerned, which may be known to the reader of a particular place and time in and out. In La jalousie, in contrast to L'appareil-photo, many such artifacts — tables, railings, chairs — are described way beyond the limits of pre-reflective comprehension.

When given too much attention, be it through meticulous description or other narrative treatment (e.g., consistent anecdotal conceptualization as in Nicholson Baker's [1986] novel The Mezzanine), mundane objects fail to coproduce presence, becoming a subject of reflection instead. However, one exception of sorts from this general rule should probably be mentioned here: touch and cutaneous sensations, or static implications thereof ("hold X," "feel $\mathrm{X}$," "X in hand," and so forth), with their double position in between proprioception and exteroception, linking the body intimately to its environment. As one moves upwards along the mundane-extraordinary continuum, more and more verbal report is needed for the mere sake of brief mentioning — without specification, the comprehender would not know what the extraordinary object 
is or that it is at all. The more elaborate a static description of an object, the higher the "risk" of conceptualization and defamiliarization.

For the description to be potentially formative of presence, an explicitly anthropocentric and egocentric (experiencer-related: e.g., "John picked up his wallet.") — as opposed to allocentric (object-related: e.g., "The wallet lay on the floor.") - way of locating the object, should preferably apply throughout the text passage, however fuzzy this distinction may be when it comes to discourse. This means for instance that a non-manipulable object should not be described from several angles at once when the locomotion required for such sensory experience cannot be sensibly inferred, given the circumstances. A description becomes truly evocative only when it captures what can directly be seen or otherwise perceived, rather than what we merely know or guess. The possibility to discern or infer a canonical perspective (see Palmer et al. 1981), i.e., a perspective facilitating canonical affordance (e.g., seeing an electric iron from above rather than from beneath), or at least human interaction of some kind, may also make a description easier to integrate into a veracious mental image.

Finally, it seems that a particularly effective way for an author to have that image feed into a genuine flash of sensorimotor unity is by making the dynamizing reference to bodily movement or touch directly after the object or immediate environment has been described in visual or other exteroceptive terms, rather than before. The reason for this is that in such cases, the movement to be enacted is readily disambiguated by the preceding text in terms of its dynamics, power, precision and sensory outcome, becoming thus in itself an ultimate "uniqueness point." See, for example, the following paragraph, taken from La jalousie:

En plein jour, l'opposition des deux couleurs grises - celle du bois nu et celle, un peu plus claire, de la peinture qui subsiste — dessine des figures compliquées aux contours anguleux, presque en dents de scie. Sur le dessus de la barre d'appui, il n'y a plus que des îlots épars, en saillie, formés par les derniers restes de peinture. Sur les balustres, au contraire, ce sont les régions dépeintes, beaucoup plus réduites et généralement situées vers le milieu de la hauteur, qui constituent les taches, en creux, où les doigts reconnaissent le fendillement vertical du bois. A la limite des plaques, de nouvelles écailles de peinture se laissent aisément enlever; il suffit de glisser l'ongle sous le bord qui se décolle et de forcer, en pliant la phalange; la résistance est à peine sensible. (RobbeGrillet 1957: 28-29)

[In broad daylight, the contrast of the two shades of gray - that of the naked wood and that, somewhat lighter, of the remaining paint — creates complicated figures with angular, almost serrated outlines. On the top of the handrail, there are only scattered, protruding islands formed by the last vestiges of paint. On the balusters, though, it is the unpainted areas, much smaller and generally located toward the middle of the uprights, which constitute the spots, here incised, where the fingers recognize the vertical grain 
of the wood. At the edge of the patches, new scales of the paint are easy to chip off; it is enough to slip a fingernail beneath the projecting edge and pry it up by bending the first joint of the finger; the resistance is scarcely perceptible. (Robbe-Grillet 1965: 48)]

After an elaborate visual opening, the paragraph gradually slides into a combined visual-tactile focus, only to be rounded off by a brief reference to transitive bodily movement, which ties the modalities together for a moment, creating a multimodal image of the railing as physically present within one's reach. Immediately after that, Robbe-Grillet's narrative brings the reader back to the realms of the purely visual again. This very reference to transitive bodily movement is not only symptomatically economic when compared to the preceding exteroceptive renditions of the environment, it also exemplifies further principles of presence cuing through bodily movement, to be outlined in what remains of this paper: it is sudden, it is comparably isolated, and it is not even grammatically bound to a particular agent or time.

\subsection{Presence as (marked) occurrence}

In his writing on the ubiquity of perspective in discourse comprehension, cognitive linguist Brian MacWhinney (2005) argues that whereas reading "the cat licked herself" in isolation may only invite us to adopt what he calls a superficial, "depictive" mode of processing (corresponding to "visualization" in Grünbaum 2007, or "visual simulation" in Zwaan 2004), reading the same sentence embedded in discourse is more likely to elicit what he calls a deeper, "enactive" mode in which the reader maps the cat's paw onto her hand (corresponding to the aforementioned "motor resonance," the basis of my "enactment"). Along with the above Robbe-Grillet quote, the embedding MacWhinney makes up for his sentence may serve as a good example for further discussion: "The cat spotted a mockingbird perched on the feeder. She crouched down low in the grass, inching closer and closer with all her muscles tensed. Just as she pounced, the bird escaped. Disappointed, she leapt up to a garden chair, raised her paw to her tongue, and began licking it." (MacWhinney 2005: 199).

Both the Robbe-Grillet quote and MacWhinney's example allow the reader to discern a unitary perspective, or even unitary focalization (e.g., Jahn 2008 [2005]) as some narratologists would have it, but grammatically they differ in person and tense, the former being impersonal. The stimulus sentences used in neuroscientific and behavioral simulation studies also vary in this respect. Enactment seems not to be reserved for selected verb forms. What applies to tense is also true for verb aspect: there may be a difference between imagery distribution (motor versus sensorimotor simulation) in punctual ("sliced an onion") 
versus iterative ("was slicing onions") action, as well as in action that is current versus past with respect to the now of the narrative (see Zwaan 2008; Zwaan et al. 2010), but resonance takes place in either case. Thus, when Käte Hamburger, an influential narratologist whose work opens for a view of presence as the hallmark of literature at large, famously argues that sentences such as "Quickly intent, he took out a leather portfolio(.)" (Hamburger 1973: 63) are exactly what makes one read a text as a literary narrative, she may be quite correct, yet her argument, grounded in the grammatical categories of person and tense, is not.

MacWhinney (2005: 199) seems to propose consistent focalization through the cat ("each clause links to the previous one through the perspective of the cat as the protagonist"), or simply the fact that the reader has been following the cat for a while by the time the critical sentence is reached, to be the main cause of motor resonance (or enactment) in reading "[she] began licking it." In opposition to this explanation, I would like to argue that the perspective intrinsic to the surrounding text and the prominence of a character in a particular passage is far less important than other circumstances: Apart from dynamic veracity and brevity of reference, which have already been treated, these can be subsumed under the tentative label of sudden modality switch. In MacWhinney, the switch entails a transition from locomotion to transitive movement (beginning one sentence earlier with "she leapt up to a garden chair"), in Robbe-Grillet it entails a transition from non-movement (or at most a little inferred micro-movement implied by tactile perception) to transitive movement. In both cases, the impact of the switch may be further reinforced by its emphatic position at the end of a paragraph. Crucially, the switch in MacWhinney's story will be preserved even if the last two sentences are replaced with a sentence referring to an animate subject other than the cat, and so will its sensorimotor appeal: "The cat spotted a mockingbird perched on the feeder. She crouched down low in the grass, inching closer and closer with all her muscles tensed. John raised the cup to his lips and took a sip of tea."

Prospection and habituation are distinctive features of all literary reading (see also Olson et al. 1981). By means of integrating subtle cues, texts continuously modulate and tease the reader's expectations. If MacWhinney's story were rich in references to transitive bodily movement (e.g., "the cat was playing with a pine cone," "she embraced the tree trunk as she observed the mockingbird") from the very beginning, or if it consisted of such references exclusively, the critical sentence would not attract as much attention, its emphatic position notwithstanding. A quality of suddenness and immediacy, crucial as it seems for full enactment to arise, would be missing then, the readers having become accustomed to the mode of transitive movement by the time they would reach the sentence. While this would probably not hinder basic motor resonance, a strong phenomenal boost toward the threshold of consciousness 
would be less likely. To recall Smith's metaphor of "periodic diet," presence cues become effective only if moderately dosed. Not only should they appear periodically, once in a while, for a continuous sense of presence to arise. They should appear just once in a while, if presence is to be instantaneously elicited at all.

Speaking of immersion in general, and its spatial facets in particular, narrative theorist Marie-Laure Ryan makes the following remark: "Continuous presence [of immersion cues] becomes habit, habit leads to invisibility, and invisibility is as good as absence. For immersion to retain its intensity, it needs a contrast of narrative modes, a constantly renegotiated distance from the narrative scene, a profile made of peaks and valleys" (Ryan 2001: 137). Neuroimaging experiments (e.g., Raposo et al. 2009) have shown that when processed in context, motor verbs cause weaker cortical activation in the motor strip than when they are processed in isolation. The immediacy of a sudden reference to bodily movement may somehow make it operate more like an isolated utterance.

Moreover, neither in Robbe-Grillet's description of the railing nor in MacWhinney's example, is transitive bodily movement overtly linked to a previously known overarching goal, or script (see Schank and Abelson 1977), e.g., in the way "picking up a fork" may in some cases be subsumed under "having dinner." The movements occur contingently, as it were. Although the framing of pre-scripted movement (e.g., "The cat wanted to clean herself, so she raised her paw to her tongue, and began licking it.") may be more productive at eliciting event-related potentials analogous to those occurring in action preparation, the slight surprise effect elicited by contingent, non-scripted movement may, on the other hand, have a reinforcing effect on resonance in a way similar to that of a sudden modality switch (see also Barthes 1989).

Discussing their results from one of the very first neuroimaging studies of story comprehension, Nicole Speer and colleagues conclude that "Regions involved in processing goal-directed human activity, navigating spatial environments, and manually manipulating objects in the real world increased in activation at points when those specific aspects of the narrated events were changing." (Speer et al. 2009: 995). Although Speer et al.'s focus is much more fundamental and granular than mine, it points in the same direction: Where movement and dynamics occur as new with regard to what immediately precedes, somatotopical resonance clearly takes place. I suggest that where they occur as comparably striking, resonance grows into enactment, and into presence.

Outlining his theory of action ownership, Marcel (2003) asserts that in real world experience, a minimal sense of action ownership (i.e., the immediate sense of performing a particular movement) can be traced to the instantaneous egocentric coordination of the senses accompanying every purposeful bodily 
action. I suggest that in reading, conversely, reflexive enactment of transitive bodily movement imposes upon the reader an instantaneously egocentric perspective, independent of narrative focalization, whereof a flash of sensorimotor unity arises. As it happens, in post-Flaubert literary prose, it is quite unusual that references to transitive bodily movement do not occur at all. But the quality of presence elicited varies significantly depending on how often and in what constellation they occur.

\section{Notes}

1. The term "presence" will thus be used here as it is commonly used in interactive media psychology (e.g., Schubert et al. 2001). See also Ryan's term "spatio-temporal immersion" (Ryan 2001).

2. Categorization of the senses varies immensely across authors and scholarly traditions. Inner senses not directly related to movement (e.g., pain) are sometimes grouped into a separate category called "interoception," which is here collapsed into the broader category of proprioception, featuring all inner senses, regardless of their relation to movement. When special emphasis is put on the motor aspects of proprioception, proprioception is referred to as kinesthesia.

3. Also, for natural objects and animals, affordances are not as central to the cognitive processes of categorization and prototype and basic-level judgment as they are in the case of artifacts (whatever we can sit on while leaning back qualifies as "chair"; see Rosch et al. 1976).

4. Symptomatically, when asked to provide a straightforward verbal account of their day, people have been found to center the discrete episodes of their narratives around artifacts of daily use (see Rosch 1978).

5. Also, it is telling that when asked to spontaneously describe enclosed environments of the kind present in La jalousie, people consistently adopt a dynamic egocentric perspective, taking their interlocutors on mental tours (see Taylor and Tversky 1996; Linde and Labov 1975).

\section{References}

Allport, Allan. 1987. Selection for action: Some behavioral and neurophysiological considerations of attention and action. In Herbert Heuer \& Andries F. Sanders (eds.), Perspectives on perception and action, 395-419. Hillsdale: Lawrence Erlbaum.

Aziz-Zadeh, Lisa, Stephen M. Wilson, Giacomo Rizzolatti \& Marco Iacoboni. 2006. Congruent embodied representations for visually presented actions and linguistic phrases describing actions. Current Biology 16(18). 1818-1823.

Baker, Nicholson. 1986. The mezzanine. New York: Weidenfeld \& Nicolson.

Barsalou, Lawrence W. 2008. Grounded cognition. Annual Review of Psychology 59. 617-645.

Barthes, Roland. 1989. The reality effect. In The rustle of language Richard Howard (trans.), 141-148. Berkeley: University of California Press.

Berthoz, Alain. 2002. The brain's sense of movement, Giselle Weiss (trans.). Cambridge, MA: Harvard University Press.

Berthoz, Alain \& Jean-Luc Petit. 2008. The physiology and phenomenology of action, Christopher Macann (trans.). New York: Oxford University Press. 
Biocca, Frank. 2002. The evolution of interactive media: Toward "being there" in nonlinear narrative worlds. In Melanie C. Green, Jeffrey L. Strange \& Timothy C. Brock (eds.), Narrative impact: Social and cognitive foundations, 97-130. Mahwah: Lawrence Erlbaum.

Borghi, Anna M. 2005. Object concepts and action. In Diane Pecher \& Rolf A. Zwaan (eds.), Grounding cognition: The role of perception and action in memory, language, and thinking, 8-34. Cambridge: Cambridge University Press.

Borghi, Anna M. \& Lucia Riggio. 2009. Sentence comprehension and simulation of object temporary, canonical and stable affordances. Brain Research 1253. 117-128.

Chao, Linda L. \& Alex Martin. 2000. Representation of manipulable man-made objects in the dorsal stream. NeuroImage 12(4). 478-484.

Ellis, Rob \& Mike Tucker. 2000. Micro-affordance: The potentiation of components of action by seen objects. British Journal of Psychology 91. 451-471.

Emmott, Catherine. 1997. Narrative comprehension: A discourse perspective. Oxford: Oxford University Press.

Engelkamp, Johannes \& Hubert D. Zimmer. 1984. Motor programme information as a separable memory unit. Psychological Research 46(3). 283-299.

Ericsson, Anders K. 2003. Valid and non-reactive verbalization of thoughts during performance of tasks: Towards a solution to the central problems of introspection as a source of scientific data. Journal of Consciousness Studies 10(9-10). 1-18.

Esrock, Ellen J. 1994. The reader's eye: Visual imaging as reader response. Baltimore: Johns Hopkins University Press.

Esrock, Ellen J. 2004. Embodying literature. Journal of Consciousness Studies 11(5-6). 79-89.

Fischer, Martin H. \& Rolf A. Zwaan. 2008. Embodied language: A review of the role of the motor system in language comprehension. Quarterly Journal of Experimental Psychology 61(6). 825850.

Flaubert, Gustave. 1999 [1857]. Madame Bovary. Paris: Librairie Générale Française.

Flaubert, Gustave. 1995 [1950]. Madame Bovary, Allan Russell (trans.). London: Penguin.

Gallagher, Shaun \& Dan Zahavi. 2007. The phenomenological mind: An introduction to philosophy of mind and cognitive science. New York: Routledge.

Gallese, Vittorio. 2000. The inner sense of action. Journal of Consciousness Studies 7(10). 2340.

Gerrig, Richard. 1998. Experiencing narrative worlds: On the psychological activities of reading. Boulder: Westview Press.

Gibson, James J. 1979. The ecological approach to visual perception. Hillsdale: Lawrence Erlbaum.

Glover, Scott, David A. Rosenbaum, Jeremy Graham \& Peter Dixon. 2004. Grasping the meaning of words. Experimental Brain Research 154(1). 103-108.

Graziano, Michael S. A. \& Charles G. Gross. 1995. The representation of extrapersonal space: A possible role for bimodal, visual-tactile neurons. In Michael S. Gazzaniga (ed.), The cognitive neurosciences, 1021-1034. Cambridge, MA: MIT Press.

Green, Melanie C. 2004. Transportation into narrative worlds: The role of prior knowledge and perceived realism. Discourse Processes 38(2). 247-266.

Grèzes, Julie, Mike Tucker, Jorge Armony, Rob Ellis \& Richard E. Passingham. 2003. Objects automatically potentiate action: An fMRI study of implicit processing. European Journal of Neuroscience 17(12). 2735-2740.

Grünbaum, Thor. 2007. Action between plot and discourse. Semiotica 165(1/4). 295-314.

Hamburger, Käte. 1973. The logic of literature, Marilynn J. Rose (trans.). Bloomington: Indiana University Press.

Iacoboni, Marco. 2008. Mirroring people: The new science of how we connect with others. New York: Farrar, Straus and Giroux. 
Jack, Anthony I. \& Andreas Roepstorff. 2003. Why trust the subject? Journal of Consciousness Studies 10(9-10). v-xx.

Jahn, Manfred. 2008 [2005]. Focalization. In David Herman, Manfred Jahn \& Marie-Laure Ryan (eds.), The Routledge encyclopedia of narrative theory, 173-177. New York: Routledge.

Jeannerod, Marc. 2006. Motor cognition: What actions tell the self. New York: Oxford University Press.

Kilner, James M., Claudia Vargas, Sylvie Duval, Sarah-Jayne Blakemore \& Angela Sirigu. 2004. Motor activation prior to observation of a predicted movement. Nature Neuroscience 7(12). 1299-1301.

Klatzky, Roberta L., James W. Pellegrino, Brian P. McCloskey \& Sally Doherty. 1989. Can you squeeze a tomato? The role of motor representations in semantic sensibility judgements. Journal of Memory and Language 28(1). 56-77.

Lewis, James W. 2006. Cortical networks related to human use of tools. Neuroscientist 12(3). 211-231.

Linde, Charlotte \& William Labov. 1975. Spatial networks as a site for the study of language and thought. Language 51(4). 924-939.

MacWhinney, Brian. 2005. The emergence of grammar from perspective. In Diane Pecher \& Rolf A. Zwaan (eds.), Grounding cognition: The role of perception and action in memory, language, and thinking, 198-223. Cambridge: Cambridge University Press.

Mar, Raymond A. 2004. The neuropsychology of narrative: Story comprehension, story production, and their interrelation. Neuropsychologia 42(10). 1414-1434.

Marcel, Anthony. 2003. The sense of agency: Awareness and ownership of action. In Johannes Roessler \& Naomi Eilan (eds.), Agency and self-awareness: Issues in philosophy and psychology, 48-93. Oxford: Clarendon.

Martin, Alex. 2007. The representation of object concepts in the brain. Annual Review of Psychology $58.25-45$.

McKoon, Gail \& Roger Ratcliff. 1992. Inference during reading. Psychological Review 99(3). $440-466$.

Miall, David S. 2006. Literary reading: Empirical \& theoretical studies. New York: Peter Lang.

Milne, A. A. 1992 [1926]. Winnie-the-Pooh. New York: Penguin.

Mukařovský, Jan. 1976. On poetic language, John Burbank \& Peter Steiner (trans.). Amsterdam: John Benjamins.

Noë, Alva. 2006. Action in perception. Cambridge, MA: MIT Press.

Olson, Gary M., Robert L. Mack \& Susan A. Duffy. 1981. Cognitive aspects of genre. Poetics 10(2-3). 283-315.

Palmer, Stephen E., Eleanor Rosch \& Paul Chase. 1981. Canonical perspective and the perception of objects. In Attention and performance IX: Proceedings of the ninth international symposium on attention and performance, Jesus College, Cambridge, England, July 13-18, 1980, 135-151. Hillsdale: Lawrence Erlbaum.

Pecher, Diane \& Rolf A. Zwaan (eds). 2005. Grounding cognition: The role of perception and action in memory, language and thinking. Cambridge: Cambridge University Press.

Perec, Georges. 1965. Les choses: Une histoire des années soixante. Paris: René Julliard.

Pflugmacher, Torsten. 2008 [2005]. Description. In David Herman, Manfred Jahn \& MarieLaure Ryan (eds.), The Routledge encyclopedia of narrative theory, 101-102. New York: Routledge.

Poe, Edgar Allan. 1984 [1844]. The purloined letter. In Complete stories and poems of Edgar Allan Poe, 125-138. New York: Doubleday.

Raposo, Ana, Helen E. Moss, Emmanuel A. Stamatakis \& Lorraine K. Tyler. 2009. Modulation of motor and premotor cortices by actions, action words and action sentences. Neuropsychologia 47(2). 388-396. 
Rapp, David N., Jessica L. Klug \& Holly A. Taylor. 2006. Character movement and the representation of space during narrative comprehension. Memory \& Cognition 34(6). 1206-1220.

Rizzolatti, Giacomo \& Vittorio Gallese. 1988. Mechanisms and theories of spatial neglect. Handbook of Neuropsychology 1. 223-246.

Robbe-Grillet, Alain. 1957. La jalousie. Paris: Minuit.

Robbe-Grillet, Alain. 1965. Jealousy. In Two novels by Robbe-Grillet, Richard Howard (trans.), 33-138. New York: Grove Press.

Robbins, Philip \& Murat Aydede (eds). 2008. The Cambridge handbook of situated cognition. Cambridge: Cambridge University Press.

Robinson, Jenefer. 2007. Deeper than reason: Emotion and its role in literature, music, and art. New York: Oxford University Press.

Rosch, Eleanor. 1978. Principles of categorization. In Eleanor Rosch \& Barbara B. Lloyd (eds.), Cognition and categorization, 27-48. Hillsdale: Lawrence Erlbaum.

Rosch, Eleanor, Caroline B. Mervis, Wayne Gray, David M. Johnson \& Penny Boyes-Braem. 1976. Basic objects in natural categories. Psychology 7. 573-605.

Ryan, Marie-Laure. 2001. Narrative as virtual reality: Immersion and interactivity in literature and electronic media. Baltimore: Johns Hopkins University Press.

Schaeffer, Jean-Marie. 1999. Pourquoi la fiction? Paris: Seuil.

Schank, Roger C. \& Robert P. Abelson. 1977. Scripts, plans, goals, and understanding: An inquiry into human knowledge structures. Hillsdale: Lawrence Erlbaum.

Schmidt, Richard A. 1975. A schema theory of discrete motor learning. Psychological Review 82(4). 225-259.

Schubert, Thomas, Frank Biocca \& Holger Regenbrecht. 2001. The experience of presence: Factor analytic insights. Presence: Teleoperators \& Virtual Environments 10(3). 266-281.

Schwartz, Daniel L. 1999. Physical imagery: Kinematic versus dynamic models. Cognitive Psychology 38(3). 433-464.

Serino, Andrea, Alessandro Farnè \& Elisabetta Làdavas. 2006. Visual peripersonal space. In Tomasso Vecchi \& Gabriella Bottini (eds.), Imagery and spatial cognition: Methods, models, and cognitive assessment, 323-335. Amsterdam: John Benjamins.

Sheets-Johnstone, Maxine. 1999. The primacy of movement. Amsterdam: John Benjamins.

Shklovsky, Viktor. 1990. Theory of prose, Benjamin Sher (trans.). Normal: Dalkey Archive Press.

Smith, Greg M. 2003. Film structure and the emotion system. Cambridge: Cambridge University Press.

Speer, Nicole K., Jeremy R. Reynolds, Khena M. Swallow \& Jeffrey M. Zacks. 2009. Reading stories activates neural representations of visual and motor experiences. Psychological Science 20(8). 989-999.

Talmy, Leonard. 2000. The windowing of attention in language. In Toward a cognitive semantics: Volume 1: concept structuring systems, 257-309. Cambridge, MA: MIT Press.

Taylor, Holly A. \& Barbara Tversky. 1996. Perspective in spatial descriptions. Journal of Memory and Language 35(3). 371-391.

Taylor, Lawrence J., Shiri Lev-Ari \& Rolf A. Zwaan. 2008. Inferences about action engage action systems. Brain and Language 107(1). 62-67.

Taylor, Lawrence J. \& Rolf A. Zwaan. 2008. Motor resonance and linguistic focus. Quarterly Journal of Experimental Psychology 61(6). 896-904.

Toussaint, Jean-Philippe. 1988. L'appareil-photo. Paris: Minuit.

Toussaint, Jean-Philippe. 2008. Camera, Matthew B. Smith (trans.). Champaign: Dalkey Archive Press.

Tucker, Mike \& Rob Ellis. 1998. On the relations between seen objects and components of potential actions. Journal of Experimental Psychology: Human Perception and Performance 24(3). $830-846$. 
Tucker, Mike \& Rob Ellis. 2001. The potentiation of grasp types during visual object categorization. Visual Cognition 8(6). 769-800.

Tucker, Mike \& Rob Ellis. 2004. Action priming by briefly presented objects. Acta Psychologica 116(2). 185-203.

Varela, Francisco J., Evan T. Thompson \& Eleanor Rosch. 1991. The embodied mind: Cognitive science and human experience. Cambridge, MA: MIT Press.

Zwaan, Rolf \& Lawrence J. Taylor. 2006. Seeing, acting, understanding: Motor resonance in language comprehension. Journal of Experimental Psychology: General 135(1). 1-11.

Zwaan, Rolf A. 2004. The immersed experiencer: Toward an embodied theory of language comprehension. Psychology of Learning and Motivation: Advances in Research and Theory 44. 35-62.

Zwaan, Rolf A. 2008. Time in language, situation models, and mental simulations. Language Learning 58(Suppl. 1). 13-26.

Zwaan, Rolf A., Lawrence J. Taylor \& Mirte de Boer. 2010. Motor resonance as a function of narrative time: Further tests of the linguistic focus hypothesis. Brain and Language 112(3). 143149.

Anežka Kuzmičová (b. 1982) is a PhD candidate at Stockholm University <anezka.kuzmicova@ littvet.su.se >. Her research interests include narrative theory, psychology of reading, and empirical methods in aesthetics. Her publications include "En myrtenkvist i högra ögat: Torgny Lindgrens Legender i möte med bysantinska helgonberättelser" (2005); and "The words and worlds of literary narrative: The tradeoff between verbal presence and direct presence in the activity of reading" (in press). 